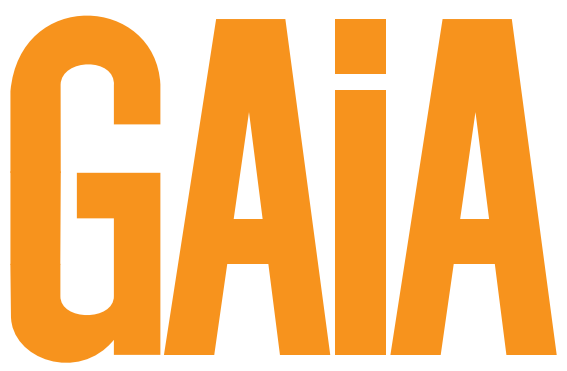
3 | 2014
ECOLOGICAL PERSPECTIVES FOR SCIENCE AND SOCIETY
ÖKOLOGISCHE PERSPEKTIVEN FÜR WISSENSCHAFT UND GESELLSCHAFT

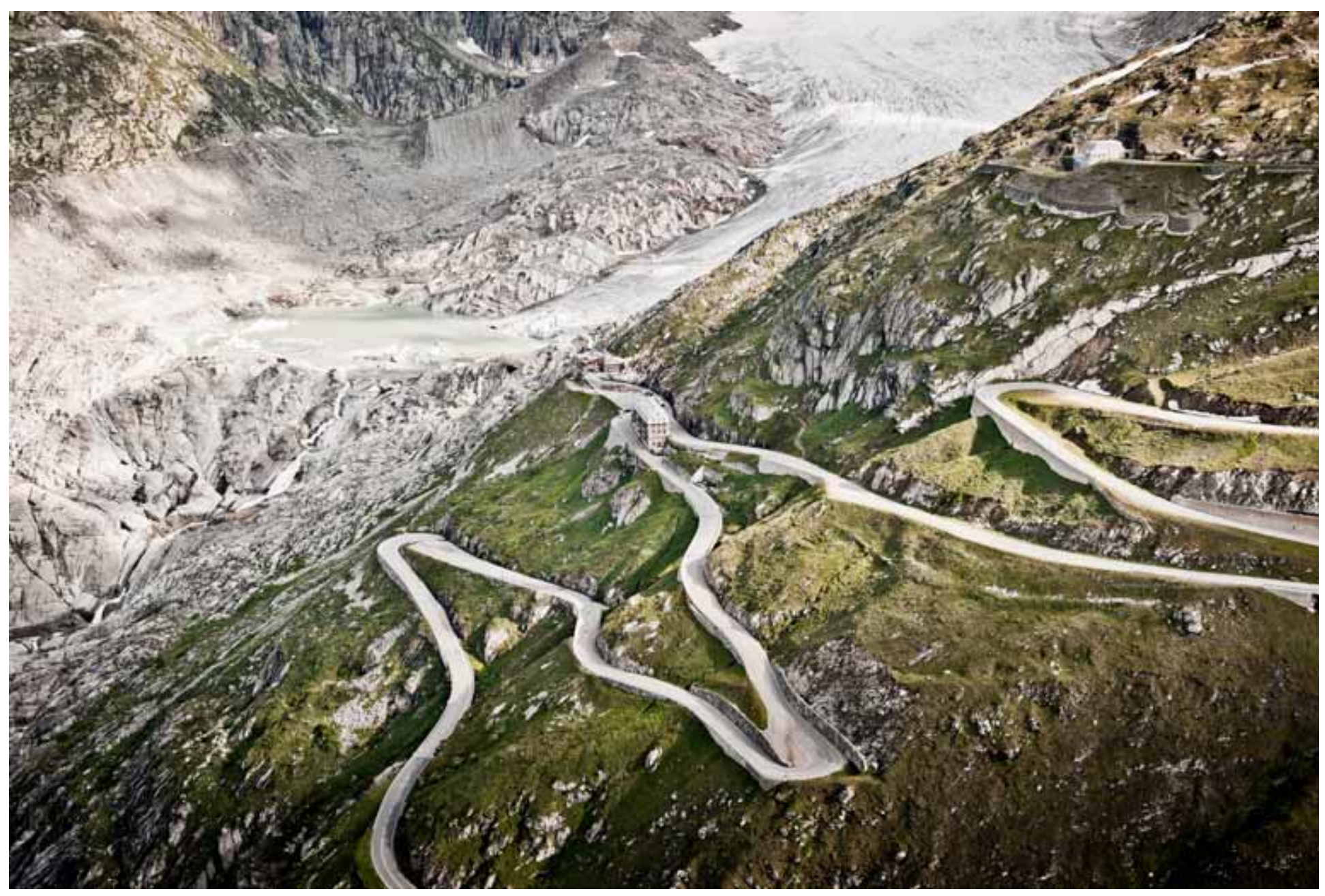

BEST PRACTICE IN TRANSDISCIPLINARY RESEARCH - COMPUTERSPIELE UND NATURETHIK KIRCHENGEMEINDEN ALS CHANGE AGENTS 


\section{The Mountain Invasion Research Network (MIREN) \\ Linking Local and Global Scales for Addressing an Ecological Consequence of Global Change}

Many modern environmental problems span vastly different spatial scales, from the management of local ecosystems to understanding globally interconnected processes, and addressing them through international policy. MIREN tackles one such "glocal" (global/local) environmental problem plant invasions in mountains - through a transdisciplinary, multi-scale learning process at the science-policy interface.

The approach led to a new framing of invasions in mountains, and promoted innovation by engaging scientists and practitioners.

Christoph Kueffer, Curtis Daehler, Hansjörg Dietz, Keith McDougall, Catherine Parks, Aníbal Pauchard, Lisa Rew, MIREN Consortium

The Mountain Invasion Research Network (MIREN). Linking Local and Global Scales for Addressing an Ecological Consequence of Global Change | GAIA 23/3 (2014): 263-265 | Keywords: boundary organization, case-study research, global change, invasive species, mountain

\section{Addressing the Multi-scale Nature of Environ- mental Problems in the "Anthropocene"}

Ongoing profound anthropogenic environmental changes on Earth are characterised by many and often interacting factors, such as changing biogeochemical cycles, vanishing biodiversity, and transformation of the last remnants of wildlands through human land use. Because of the global extent and synchrony of many of these changes, scientists often refer to them collectively as "global change". However, changes, and their consequences, happen at different spatial scales. The multi-scale nature, typical of many environmental problems, requires integrating expertise and action across all scales (from local to global), posing particular challenges for transdisciplinary research. The Mountain Invasion Research Network (MIREN) ${ }^{1}$ is designed to address a complex global change issue, biological invasions, through a multi-scale learning process at the science-policy interface.

\section{Plant Invasions in Mountains}

Biological invasions are threatening biodiversity and ecosystem services throughout the world. They represent a transdisciplinary problem involving both natural and social processes, touching upon controversial value-laden issues (e.g., native/non-native, natural/artificial, uncertainty and ignorance, precautionary principle), and requiring multi-agency and multi-stakeholder solutions across multiple spatial scales, from the management of local natural areas to the regulation of global trade (Kueffer and Hirsch

1 www.miren.ethz.ch
Hadorn 2008, Richardson 2011, Kueffer 2013, Humair et al. 2014). The expert field of biological invasions is unique insofar as it has a 50-year history of addressing a complex environmental problem through problem-oriented and interdisciplinary research (Kueffer and Hirsch Hadorn 2008). Moreover, mountains are a particularly good study system to develop and test a multi-scale transdisciplinary research approach that supports anticipatory and proactive policy responses. Mountain ecosystems are still relatively uninvaded (Pauchard et al. 2009), they share many similarities on different continents and in different climate zones, and there is a globally connected mountain expert community.

\section{The Mountain Invasion Research Network (MIREN)}

Founded in 2005, MIREN is a boundary organization that bridges across scales and expert groups to understand invasion processes and support preventive measures against future invasion. Four elements are pivotal:

Global network of local case studies: MIREN links local scales with the global scale. It encompasses eleven case-study sites carefully selected from different ecological (subarctic to tropical, continents and islands) and socioeconomic contexts (developed and develop-

Contact: PD Dr. Christoph Kueffer | ETH Zurich | Institute of Integrative Biology | Universitätstr. 16 | 8092 Zurich | Switzerland | Tel.: +41446328759 | E-Mail: christoph.kueffer@env.ethz.ch

C 2014 C. Kueffer et al.; licensee oekom verlag. This is an Open Access article distributed under the terms of the Creative Commons Attribution License (http://creativecommons.org/licenses/by/3.0), which permits unrestricted use, distribution and reproduction in any medium, provided the original work is properly cited. 


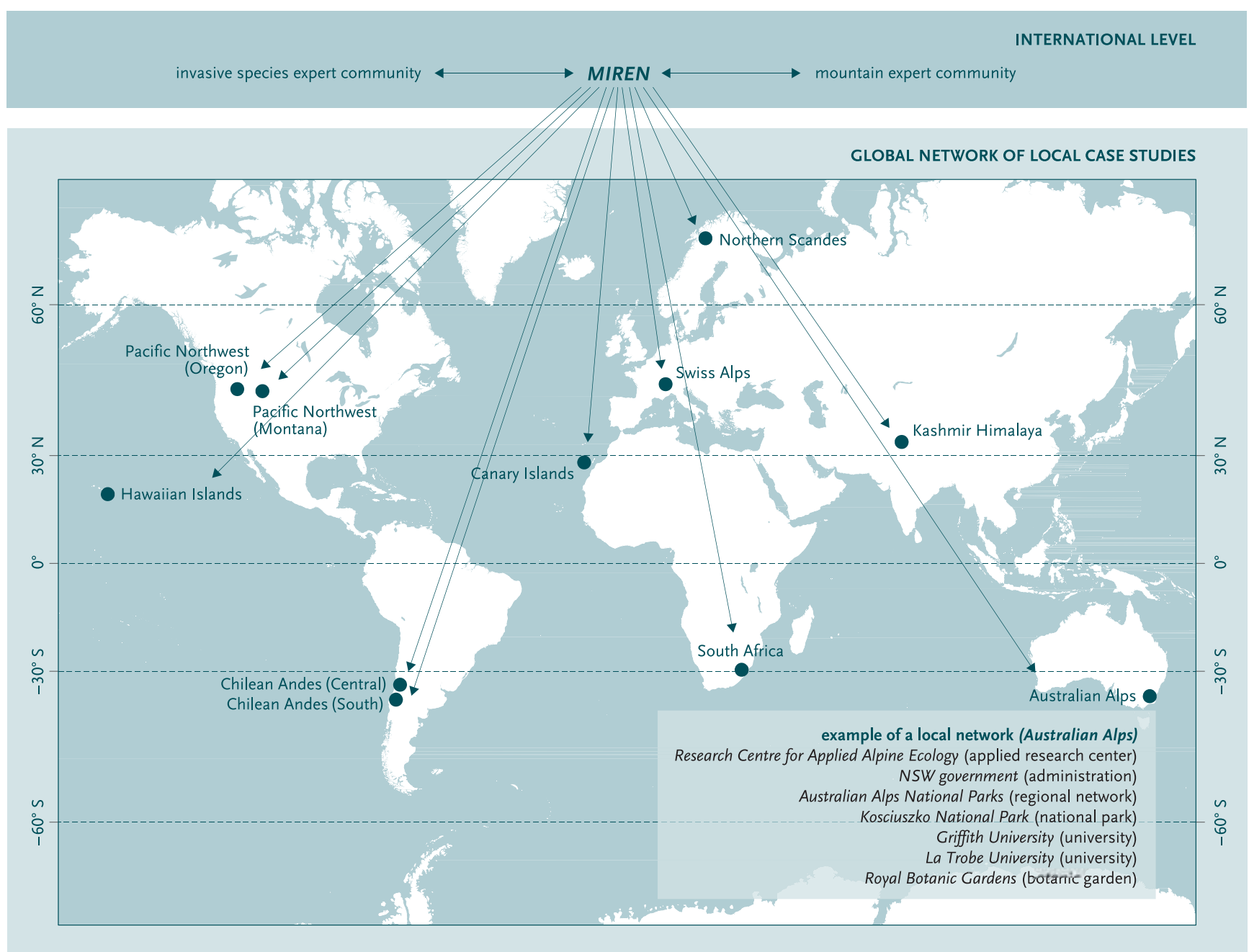

FIGURE: The multi-scale science-policy network of MIREN. Local multi-agency networks form the basis of eleven case-study sites that are distributed across different climate zones and socioeconomic contexts. At an international level, MIREN bridges the interdisciplinary fields of expertise on invasive species and mountain science/management. Made with Natural Earth map data, see www.naturalearthdata.com.

ing countries), including both research and management institutions at all sites (see figure). It aims to strengthen anticipatory research and precautionary management through replicated local case studies and cross-site learning. Through its integration at the global scale with existing international invasive species and mountain networks such as the Global Mountain Biodiversity Assessment (GMBA) and Mountain Research Initiative (MRI), it reaches out to the broader research and management communities.

Inter- and transdisciplinary "community of practice": MIREN links two interdisciplinary fields of expertise on invasive species and mountains, respectively. Its scientific and outreach publications explicitly target both expert fields. MIREN members - experts from academia and management institutions - meet biennially at a case-study site to: 1 . maintain strong personal relationships among members with contrasting geographic and professional backgrounds, 2. discuss cross-site and local research projects, 3 . acquire experience-based knowledge about study systems through field visits, and 4. interact with local managers and policy makers. Two chairs (that rotate every two years and are from academic and management institutions) represent MIREN . ${ }^{2}$
Open-ended, long-term process: MIREN is funded through small grants and in-kind funding raised by the local teams. Such bottom-up funding allows for adapting activities continuously in response to scientific insights and emerging management needs, and ensures that all members are personally committed to the project.

Focused empirical research: MIREN performs standardized research (observational and experimental) across all sites, plus regionally-based associated research. Involvement in focused research is important for structuring discussions, nurturing creativity, and forming shared understandings and interests. Thanks to its structure, MIREN is exceptionally well positioned to perform research that integrates in-depth studies about particular ecosystems or species at a local scale with statistical analysis of large datasets from many invasions worldwide at a global scale (Kueffer et al. 2013); as illustrated by publications in leading scientific journals (e. g., Alexander et al. 2011).

2 The main co-authors include all MIREN chairs since its inception in 2005. 


\section{MIREN's Successes}

MIREN has framed invasion risks in mountains in a new way by identifying human history as the primary reason for low levels of invasion at increasing elevation. Historically, non-native species were moved from one lowland area to another and these new floras did not contain mountain specialists; therefore only species with broad climate niches have reached high elevations (Alexander et al. 2011). However, the increase in tourism, recreation and residential habitation in mountains results in non-native horticultural mountain specialists being introduced to higher elevations. These ecologically novel non-native species pose a far greater invasion risk to mountain ecosystems. Thus, proactive management of invasion risks in mountains should anticipate socioeconomic change and focus on emerging introduction pathways of new species (McDougall et al. 2011); an insight that is of very general importance for invasive species management in a time of rapid societal change (Kueffer et al. 2013).

Mountain invasions are now recognized as a conservation issue by local, regional and international policy makers (e.g., Intergovernmental Panel on Climate Change). MIREN engages in mutual relationships with practitioners and policy makers in all case-study sites for developing locally-adapted solutions (McDougall et al. 2011). MIREN has established a "community of practice", which is global but locally-rooted and capable of addressing diverse multi-scale global change problems in mountains. At a local scale scientists and managers collaborate to understand the context-specific dimensions of plant invasions and their management. Such local knowledge is exchanged and cross-validated through personal encounters among scientists and practitioners from multiple sites. Emerging concerns that require international policy responses - such as weed risk assessments specific to mountains or databases as a basis for preventive action - are infused into international science and policy bodies among others through MIREN's partner organizations (e.g., Global Change in Mountain Regions conference series co-organized by MRI or policy-oriented activities of GMBA).

Building on such institutional capacity, MIREN is expanding its scope by collaborating with plant pathologists and zoologists to understand all type of bio invasions in mountains and by addressing other global change impacts on mountain vegetation.

\section{Conclusions}

Many modern environmental problems span vastly different spatial scales from the management of local ecosystems to understanding globally interconnected processes and addressing them through international policy. The institutional model of MIREN illustrates how such glocal environmental problems can be addressed through a cost-effective, rapid and transdisciplinary research and policy process. A key idea is complementarity: MIREN builds on existing institutions at a local and international level but focuses on a specific problem.

\section{References}

Alexander, J. M. et al. 2011. Assembly of non-native floras along elevational gradients explained by directional ecological filtering. Proceedings of the National Academy of Sciences of the United States of America (PNAS) 108: 656-661.

Humair, F., M. Siegrist, P. J. Edwards, C. Kueffer. 2014. Understanding misunderstandings in invasion science: Why experts don't agree on common concepts and risk assessments. Neobiota 20: 1-30.

Kueffer, C. 2013. Integrating natural and social sciences for understanding and managing plant invasions. In: Biodiversity and Society in the Pacific Islands. Edited by S. Larrue. Aix-en-Provence: University Press of Provence (PUP), Canberra: ANU ePress. 71-96.

Kueffer, C., G. Hirsch Hadorn. 2008. How to achieve effectiveness in problemoriented landscape research: The example of research on biotic invasions. Living Reviews in Landscape Research 2: 2. doi:10.12942/Ir|r-2008-2.

Kueffer, C., P. Pyšek, D. M. Richardson. 2013. Integrative invasion science: Model systems, multi-site studies, focused meta-analysis, and invasion syndromes. New Phytologist 200: 615-633.

McDougall, K. L. et al. 2011. Plant invasions in mountains: Global lessons for better management. Mountain Research and Development 31: 380-387.

Pauchard, A. et al. 2009. Ain't no mountain high enough: Plant invasions reaching new elevations. Frontiers in Ecology and the Environment 7: 479-486.

Richardson, D. M. (Ed.). 2011. Special issue: Human-mediated introductions of Australian acacias - A global experiment in biogeography. Diversity and Distributions 17: 771-1075.

Submitted May 26, 2014; revised version accepted July 9, 2014.

CONTRIBUTING AUTHORS

PD Dr. Christoph Kueffer

Dr. Hansjörg Dietz

both: ETH Zurich, Institute of Integrative Biology, Zurich, Switzerland

Prof. Dr. Curtis Daehler

University of Hawaii at Manoa, Department of Botany, Honolulu, HI, USA

Dr. Keith McDougall

La Trobe University, Department of Environmental Management and Ecology, Wodonga, Australia

Dr. Catherine Parks

U.S. Forest Service, Pacific Northwest Research Station, La Grande, OR, USA

Prof. Dr. Aníbal Pauchard

Universidad de Concepción, Facultad de Ciencias Forestales, and Institute of Ecology and Biodiversity (IEB), Concepción, Chile

Prof. Dr. Lisa Rew Montana State University, Land Resources and Environmental Sciences Department, Bozeman, MT, USA

MIREN Consortium Jake Alexander, José Ramón Arévalo, Lohengrin Cavieres, Peter J. Edwards, Sylvia Haider, Lloyd Loope, Richard N. Mack, Ann Milbau, Bridgett J. Naylor, Rüdiger Otto, Fred Pollnac, Zafar A. Reshi, Ian Rushworth, Tim Seipel, Neville Walsh

Christoph Kueffer

PhD in environmental sciences (2006) and habilitation in plant and global change ecology (2013) from ETH Zurich, Switzerland. Project manager of MIREN since the start of the project in 2005 and senior scientist at ETH Zurich. Research interests: plant ecology, global change ecology, mountains, oceanic islands, invasive species, transdisciplinary environmental research, environmental humanities. 